\title{
APROPRIAÇÃO DOS ESPAÇOS PÚBLICOS PELA SOCIEDADE: O CONTRASTE ENTRE BALNEÁRIO MUNICIPAL DE ROSANA -SP E AMBIENTES PÚBLICOS PLANEJADOS
}

\author{
Stephanie Dias Germano, Yeda Ruiz Maria
}

Universidade do Oeste Paulista - UNOESTE, Curso de Arquitetura e Urbanismo, Presidente Prudente, SP. E-mail: stephaniedias_germano@hotmail.com

\section{RESUMO}

O presente artigo objetiva mostrar por meio de estudos bibliográficos como um espaço público, sendo ele projetado e planejado, em contraposição a espaços que surgiram na malha urbana, sem um adequado planejamento, são capazes de modificar o uso e as relações sociais ali presentes. Um o incentivando e proporcionando-o adequadamente, e outro consecutivamente, por suas falhas, minimizando-o. Como exemplo do Balneário Municipal de Rosana - SP, comparando com cidades conceituadas que possuem estratégias bem-sucedidas, visando de maneira sucinta incentivar e demonstrar a relevância do homem como figura de inspiração no momento do planejamento urbano, assim como a importância do planejamento em si, e sua fundamental influência na vida em sociedade.

Palavras-chave: Espaço público; Planejamento urbano; Balneário Municipal de Rosana - SP.

\section{APPROPRIATION OF PUBLIC SPACES BY THE SOCIETY: THE CONTRAST BETWEEN THE ROSANA - SP MUNICIPAL SPA AND PLANNED PUBLIC ENVIRONMENTS}

\begin{abstract}
The present article aims to show through bibliographical studies how a public space, being designed and planned, as opposed to spaces that have emerged in the urban network, without adequate planning, are able to modify the use and the social relations present there. One encouraging and providing it properly, and another one consecutively, by its flaws, minimizing it. As an example of the Rosana - SP Municipal Spa, comparing with wellknown cities that have successful strategies, aiming succinctly to encourage and demonstrate the relevance of man as a figure of inspiration at the time of urban planning, as well as the importance of planning itself, and its fundamental influence on life in society.
\end{abstract}

Keywords: Public place; Urban planning; Rosana - SP Municipal Spa. 


\section{INTRODUÇÃO}

A cidade é um lugar construído dividido por espaços públicos, abertos à todos, e espaços privados, de acesso limitado, ela se consolida com tudo o que a constitui: o trânsito, o barulho, as ruas por onde circula uma população mais ou menos apressada, as praças, os jardins ou outros espaços que fazem parte da esfera pública, ocupados por diferentes pessoas em horas diversificadas e que são essenciais à comunicação e socialização.

\section{A}

cidade vive uma constante mudança e nela surgem novas fórmulas de vivência urbana comandadas pela economia, pela globalização das práticas culturais e territoriais, pela mobilidade crescente que transforma o cotidiano. O ordenamento dos espaços públicos, sobretudo os de lazer, é atualmente um dos aspectos vitais para a revitalização e a qualidade de vida no meio urbano. $\quad 0$ espaço público tem uma função, e esta pressupõe um uso. A essência do espaço público está na forma como é utilizado pelos atores sociais, ou seja, das práticas que possa acolher, que torne possível ou até oportunize, podendo a sua forma, favorecer ou inibir essas práticas. Gehl (2015) enfatiza que a função social do espaço da cidade, como local de encontro, contribui para os objetivos da sustentabilidade social e para uma sociedade democrática aberta.

Existe uma estreita ligação entre o uso do espaço público pelas pessoas, a qualidade desse espaço e o grau de preocupação com a dimensão humana. Nesta vertente o objetivo deste estudo é mostrar como um espaço público, sendo ele projetado e planejado, em contraposição a espaços que surgiram na malha urbana sem um adequado planejamento, como o Balneário Municipal de Rosana -SP, são capazes de modificar o uso e as relações sociais ali presentes, entendendo assim o como o planejamento urbano influencia diretamente na vida das pessoas.

\section{METODOLOGIA}

O presente trabalho empregou pesquisas à livros de estudiosos de arquitetura e urbanismo, pesquisa de campo e manifestações relevantes na matéria objeto de estudo, utilizando o método comparativo para sistematizar os dados coletados.

\section{RESULTADOS}

Os espaços públicos desempenham diversas funções na cidade: recreação, respiro para o ambiente urbano densificado, identidade para bairros ou até mesmo cidades inteiras, embelezamento do espaço urbano, possibilidade de interação e convívio social. Sendo este um uso que já não se faz só em função das dimensões objetivas dos indivíduos, como idade, gênero, habilitações, classe social, estilo de vida, etc., mas cada vez mais se incorporam outros aspectos mais subjetivos, como as motivações, os desejos e os valores dos indivíduos, dessa forma a dimensão simbólica ganha mais força, os espaços passam a ser utilizados também pela sua imagem, qualidade e conforto.

Nas cidades apresenta-se um sistema de espaços livres aliado ao processo de produção do mercado imobiliário, parcelamento do solo e formas de propriedade, tanto legalmente constituídos, quanto provenientes da ilegalidade na ocupação das terras e de seu parcelamento. Prevalece no desenho urbano, a cultura da terra como mercadoria de consumo, reforçada por políticas e ações públicas que historicamente não foram eficazes na distribuição equitativa de infraestrutura urbana, que é o caso do Balneário Municipal de Rosana - SP, inaugurado em maio de 1998, sua infraestrutura conta com banheiros, com duchas, estacionamentos, quadras de areia, campo de futebol, playground para as crianças, 
policiamento e corpo de bombeiros.

Serpa (2014) questiona que uma vez implantado, o parque se transmuta em formas, começa o tempo de sua legitimação por meio da apropriação social das formas pelos usuários e termina o paradoxo entre forma e discurso. $\mathrm{O}$ autor questiona ainda sobre o que acontece uma vez que o parque passa a ser "lido" e "vivido" na paisagem urbana. O presente artigo entende que o usuário se manifesta a respeito do espaço através de suas próprias atitudes.

Os usuários são raramente objeto de grande interesse por parte dos agentes que viabilizam a implantação dos parques púbicos. No entanto, por suas práticas espaciais e suas estratégias de representação, eles acabam por forjar novos discursos, relacionados à crítica aos lugares que frequentam, aos comportamentos às atitudes e as lógicas de apropriação espacial. As trilhas e os caminhos espontâneos dos gramados, os bancos ignorados ou disputados, as incivilidades cometidas em determinados lugares...Todas essas apropriações devem ser interpretadas como discursos (SERPA, 2014, p.76).

Esse não pensar no usuário ocasiona uma frequência muito pequena de pessoas durante a semana no Balneário Municipal de Rosana - SP, tendo um fluxo mínimo durante a tarde e um pouco mais ao entardecer, quando a intensidade do sol é menor e de noite torna-se um lugar hostil, sem movimento. A ideia de crescimento econômico, muitas vezes confundida com desenvolvimento, é um fator bastante presente na realidade de muitos países. Desse modo, é impossível tratar de desenvolvimento ou crescimento sem levar em consideração o capitalismo, modo de produção predominante no mundo. Surgem com esse desenvolvimento as cidades em decorrência da necessidade de liberdade e motivadas pela atividade comercial, florescem os espaços urbanos, com suas localizações influenciadas por aspectos positivos, próximas às estradas e rios.

A cidade de Rosana - SP se desenvolveu sem planejamento urbano adequado, foi se expandindo naturalmente. No Plano Diretor de Turismo (2015) elaborado pela Prefeitura Municipal alega-se que a taxa de urbanização de Rosana, é de $80,53 \%$, o que significa que a população urbana do município é maior que a população rural, sendo que da população total, 3.833 pessoas são da área rural, e 15.858 vivem em área urbana. Sendo assim, existem atualmente 9.780 homens e 9.911 mulheres no município (ROSANA, 2015). Preocupante o fato de que essas pessoas não utilizam seu tempo livre na principal área de lazer da cidade. O sociólogo francês Dumazedier (2001, pg. 94), caracterizou lazer como:

[...] um conjunto de ocupações às quais o indivíduo pode entregar-se de livre vontade, seja para repousar, seja para divertir-se, recrear-se e entreter-se ou ainda, para desenvolver sua informação ou formação desinteressada, sua participação social voluntária ou sua livre capacidade criadora após livrar-se ou desembaraçar-se das obrigações profissionais, familiares e sociais.

$\mathrm{Na}$ imagem a seguir pode ser observado que em dias comuns de semana a frequência de pessoas no local é extremamente escassa. 
Figura 1. Vista aérea Balneário Municipal de Rosana em dia de semana.

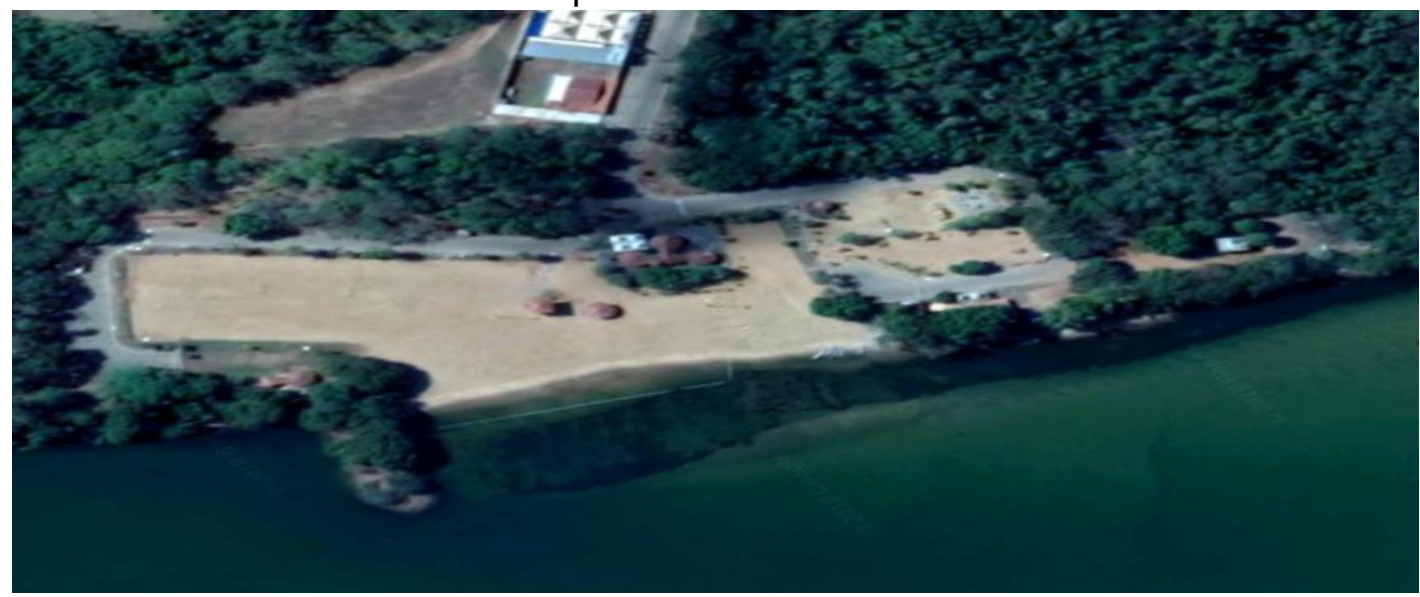

Fonte: Google Maps, 2018.

Logo, observa-se que a impossibilidade dos usuários de cometer as ocupações citadas por Dumazedier (2001), acabam em descaso com o ambiente, o tornando inútil. A população não se sente atraída em usufruir do local, ele deve abranger espaços destinados ao descanso, a diversão, e que fomentem manifestações culturais e usos em todas as suas classificações quanto cultura e lazer, estes que também devem ser dispostos de maneira a atrair os usuários, fazendo do espaço projetado não apenas um projeto, mas sim, um lugar. Caso um portador de necessidades especiais queira chegar até a orla do Balneário Municipal de Rosana - SP, esse seria impossibilitado, ou o pedestre quisesse ir até lá andando, ou sentar e ler um livro na sombra, isso também não seria possível, pois a vegetação nestas áreas são pontuais e insuficientes. Gehl (2015), alega que todos os tipos de pessoas independente da sua classe social, idade ou raça devem se sentir confortáveis e se sentir convidados a usar o ambiente projetado, diz ainda que:

É significativo que todos os grupos sociais possam se encontrar nesses espaços, ao se deslocarem para suas atividades diárias. Essa é uma boa forma de fornecer informação geral para qualquer um sobre a composição da universalidade da sociedade. Além disso, faz com que as pessoas sintam-se mais seguras e confiantes quanto a experimentar os valores humanos comuns reproduzidos em diferentes contextos (GEHL, 2015, p. 28).

Com isso, reforça-se a necessidade de espaços, tanto que incentivem a cultura, ou até mesmo para descanso, mobiliários e paisagismo, que viabilizem a permanência dos usuários, a ausência destes justifica o descaso da população frente ao Balneário Municipal de Rosana-SP como ambiente de lazer.

Em contraponto, o Balneário Municipal de Rosana - SP, tem sua frequência de pessoas aumentada em épocas festivas, devido aos Shows promovidos pela Prefeitura Municipal, e atividades turísticas nas chamadas altas temporadas, baseando-se nisso, convém falar sobre a questão do consumo que acaba por modificar as reais funções dos ambientes públicos.

[...] os parques se assemelham cada vez mais aos shoppings centers com a valorização do consumo como atividade de lazer, restaurantes e bares parecem ser a principal atração do lugar para os moradores da cidade embora a lagoa continue a atrair turistas de procedências diversas [...] é como se os caminhos do projeto evitassem de maneira intencional a lagoa, partindo do pressuposto de que para preserva-la da depredação humana o melhor seria segrega-la (SERPA, 2014, p. 25). 
Serpa (2014) diz que a alteração dos referenciais culturais das áreas de urbanização popular, a partir da mercantilização de suas manifestações artísticas, transforma radicalmente os espaços públicos dos bairros populares, agora instrumentalizados pela lógica do capitalismo para multiplicar produção e consumo. Isso pode ser visto claramente na rotina do local de estudo, vendedores ambulantes, passeios de barco, passeios de boia, as relações comerciais intensificam-se, e a cidade acaba por girar ao redor dos eventos festivos, que visam o lucro em primeira posição e depois o bem estar e qualidade de lazer oferecido aos usuários, porém, passado as festas tudo isso acaba.

No Carnaval e Festas de Réveillon o público estimado, segundo Rosana (2015), chega a seis mil pessoas por dia (FIGURA 2).

Figura 2. Último dia de Carnaval, 2015.

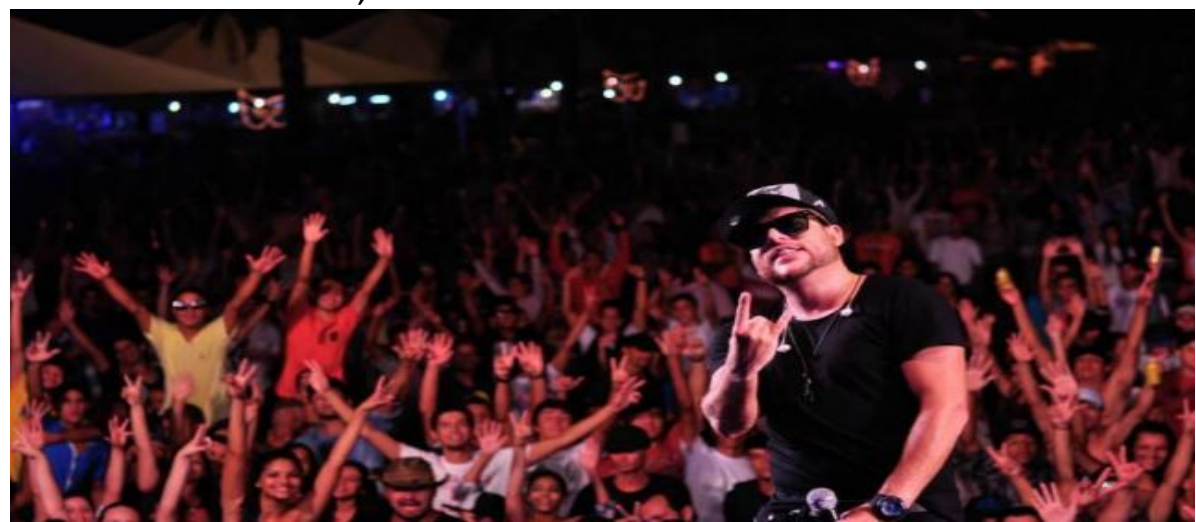

Fonte: Rosana, 2015.

O que Serpa diz sobre isso é que:

No período contemporâneo, o "consumo cultural" parece ser o novo paradigma para o desenvolvimento urbano. As cidades são reinventadas a partir da reutilização das formas do passado, gerando uma urbanidade que se baseia, sobretudo, no consumo e na proliferação (desigual) de equipamentos culturais. Nasce a cidade da "festa-mercadoria". Essa nova (velha) cidade folcloriza e industrializa a história e a tradição dos lugares, roubando-lhes a alma. É a cidade das requalificações e revitalizações urbanas, a cidade que busca vantagens comparativas no mercado globalizado das imagens turísticas e dos lugaresespetáculo (SERPA, 2014, p. 107).

Por meio deste exemplo, pode se observar os erros de planejamento e as justificativas da falta de frequência de pessoas no local de estudo, houve uma inversão da real função do Balneário Municipal de Rosana -SP como área de lazer, acentuado pela falta de infraestrutura adequada e pela promoção de festas que passaram a ser a principal característica do local. Por meio disso, como uma maneira de mostrar que é possível haver mudanças mesmo após o local estar consolidado, em oposição será explanado sobre espaços que tiveram um replanejamento e que obtiveram resultados positivos quanto a seus objetivos e quanto a reação das pessoas sobre eles. De acordo com os relatos de Gehl (2015, p.11):

A cidade de Copenhague vem reestruturando sua rede viária há décadas, removendo faixas para automóveis e áreas de estacionamento em um processo deliberado para criar condições melhores e mais seguras para o trafego de bicicletas. Ano após ano, os habitantes da cidade são convidados a pedalar mais. 
Toda a cidade agora é servida por um adequado e eficaz sistema de ciclovias, separadas das calçadas e das faixas de automóveis por meios-fios. As intersecções da cidade têm faixas para bicicletas pintadas de azul, e semáforos especiais mudam para o verde seis segundos antes do que para os carros, deixando muito mais seguro o pedalar pela cidade. Em resumo, um claro convite estendido aos ciclistas e os resultados refletem-se claramente nos padrões de uso da cidade. O movimento de bicicletas dobrou de 1995 a 2005 e, em 2008, as estatísticas mostraram que 37\% do transporte pessoal do e para o trabalho e escolas eram feitos por bicicleta.

Outro exemplo de planejamento, voltado e pensado para as pessoas e a qualidade de vida, que foi bem-sucedido, explanado por Gehl e da cidade de Melbourne:

Por volta de 1980, a área central de Melbourne era uma coleção indiferente de escritórios e torres, sem vida e sem uso. A cidade tinha o apelido de "rosquinha", porque era vazia no centro. Em 1985, iniciou-se um extenso projeto de renovação urbana para transformar o centro em um polo atrativo e cheio de vida para os mais de três milhões de habitantes da região. [...] De 1994 a 2004, implantou-se uma quantidade impressionante de melhorias urbanas. [...] O fator mais extraordinário foi, o entanto, a intenção de convidar as pessoas a caminhar pela cidade. [...] as calçadas foram aumentadas, novos pisos criados com a utilização de pedra local, basalto azul, e criou-se um novo mobiliário urbano, com bons materiais. O perfil da cidade confortável às pessoas foi seguido por uma extensa estratégia verde que incluía o plantio anual de quinhentas novas árvores para proteger o caráter local e para dar sombra as calçadas. Um programa amplo de arte na cidade e um bem elaborado sistema de iluminação noturna completam o quadro de uma cidade que tem perseguido uma política dedicada a criar convites para movimentação e permanência de pedestres. Elaborados em 1994 e 2004, dois grandes levantamentos sobre o tipo de vida nos espaços públicos mostram que tanto a movimentação de pedestres quanto as atividades de maior permanência aumentaram notadamente em consonância com as muitas melhorias urbanas. No geral a movimentação de pedestres durante a semana, na área central de Melbourne, aumentou 39\% durante o dia, enquanto o uso noturno da cidade pelos pedestres dobrou. [...] As novas praças, largas calçadas e passagens recém reformadas oferecem muitas novas e atrativas possibilidades de permanência e o nível de atividade quase triplicou em dias de semana normais (GEHL, 2015, p.15).

\section{DISCUSSÃO}

De acordo com Reis Alves (2004), somente com a interrelação das esferas espaciais, ambientais e humanas, um espaço torna-se um lugar. Sem os atributos humanos, o espaço não é um lugar, mas apenas um local onde todos os atributos espaciais e os ambientais agem, porém sem a interação humana, sem os valores humanos. Logo o que se deduz é que - Balneário Municipal de Rosana -SP é apenas um espaço e nele há a necessidade dessas relações socais que podem ser obtidas sim, através de um replanejamento urbano que vise viabilizar de maneira mais agradável, as atividades sociais dos cidadãos Rosanenses, turistas e afins em todas suas dimensões, pois se o espaço da cidade for desolado e vazio, nada acontece. A sociedade tem uma constante necessidade de novas informações sobre as pessoas e a vida, à medida que ela acontece, e sobre a comunidade ao redor, novas informações são conseguidas não importa onde as pessoas estejam e, portanto, em grande parte no espaço comum da cidade, fomentar o uso do ambiente em estudo não se limita apenas na qualidade de vida individual de cada pessoa, de cada cidadão, mas na união da comunidade. 
"Uma cidade que convida as pessoas a caminhar, por definição, deve ter uma estrutura razoavelmente coesa que permita curtas distancias a pé, espaços públicos atrativos e uma variedade de funções urbanas" (GEHL, 2015, p.06). Por meio de uma observação mais aproximada dos estudos sobre a vida na cidade, percebe-se que, uma após outra, nas cidades onde as condições para vivenciar o trafego a pé, as condições de permanência, e a variedade de usos são melhoradas, a gama de atividades desenvolvidas por esse meio aumenta de forma significativa, vê-se inclusive um crescimento mais amplo nas atividades sociais e de recreação (GEHL, 2015).

Após a comparação entre o Balneário Municipal de Rosana -SP, sendo explanado suas condições e sua frequência insignificante de pessoas, com os espaços narrados por Gehl (2015), que após um replanejamento provou um novo olhar das pessoas sobre eles e uma restauração da frequência dos usuários, vê-se uma alternativa cabível e viável para ser aplicada em Rosana -SP, reforçando a importância do planejamento dos espaços públicos, e os benefícios que seus usos, disponibilizados adequadamente, podem trazer.

\section{CONCLUSÃO}

Por meio destes exemplos o que pode ser observado é que quando existem espaços pensados e projetados para o usuário, e que a intenção é fomentar o uso, e trazer a sociedade e as relações sociais para aquele espaço, ele se torna um projeto completo, seu uso pela comunidade será constante e natural e ele não será somente um espaço, mas sim um lugar, um lugar com vida.

Ao contrário do que se viu por exemplo, no Balneário Municipal de Rosana - SP, que é um espaço com pouco planejamento, e que não fornece suporte adequado e suficiente para as pessoas fazerem dele um ambiente ao qual frequentarão cotidianamente, que tem um público grande sim, pontualmente em eventos promovidos visando o lucro, que não deve ser o foco principal, pois este seria uma consequência natural de um espaço que é sempre frequentado e que fornece qualidade de vida.

Por meio disso, vê-se o quão fundamental é o planejamento de espaços públicos, principalmente quando pensado em como seus frequentadores, em toda sua diversidade, querem usá-lo, e nele colocar os mais variados benefícios, dos quais a comunidade poderá usufruir, independentemente de sua idade, cultura ou raça.

\section{REFERÊNCIAS}

DUMAZEDIER, J. Lazer e cultura popular- Debates. 3 ed. São Paulo: Perspectiva. 2001.

GEHL. J. Cidade para pessoas. 3 ed. São Paulo: Editora Perspectiva. 2015.

REIS ALVES, L. A. dos. O conceito de lugar. Rio de Janeiro: Universidade Federal do Rio de Janeiro. Faculdade de Arquitetura e Urbanismo. 2004. il.. 10 p. Mimeografado. ISBN 332544.

ROSANA, Prefeitura Municipal de. Divisão de Turismo e Cultura. Plano Diretor de Desenvolvimento Turístico do Município de Rosana - SP. 2015. Disponível em: <http://www.rosana.sp.gov.br/plano-diretor-de-turismo/Plano-Diretor-DesenvolvimentoTuristico-Municipio-Rosana.pdf> Acesso em: 10 Jul. 2018. 
SERPA, A. 0 espaço público na cidade contemporânea. 2 ed. São Paulo: Editora contexto. 2014. 